\title{
Integrated Environmental Permitting Process in Slovakia
}

\author{
Kralikova, R.; Rusko, M.; ProchadZKova, D. \& WeSSEly, E.
}

Abstract: Integrated environmental permits is a topical issue in many Europe countries such as Slovakia. An integrated system of prevention and control of pollution was recommended in the early '90s because of the recognition that regulation over the release of substances into one environmental medium (e.g. air, land, water, waste ) can result in shifting the substance to another medium. By industrial activities is then divided also the field of these activities. Integrated prevention and industrial pollution protection is a set of measures aimed at pollution prevention, reduction of emissions to air, water and soil, reduction of waste generation and at waste recovery and disposal in order to achieve a high level protection of the environment taken as a whole, whereas is focusing on industrial sphere. This paper deals with integrated pollution and prevention control which presents a shift from keeping each environmental sector to industrial activities.

Key words: Environment, permit, prevention, BAT and BREFs
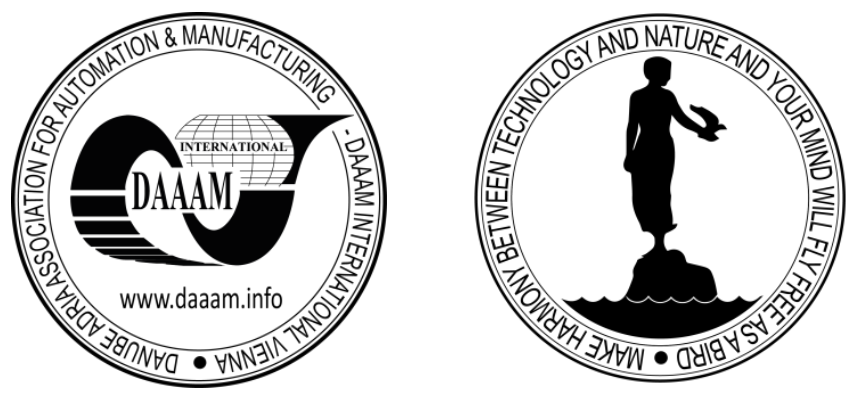

Authors' data: Assoc.Prof., dipl.Ing., PhD. Kralikova, R[uzena]*; Assoc.Prof., RNDr., PhD. Rusko, M[iroslav ]**, Assoc. Prof.,Ing. PhD. Prochadzkova, D[ana] \& Assoc.Prof.,dipl. Ing., PhD.Wessely, E[mil], *Technical University of Kosice, Letna 9, 040 01, Kosice, Slovakia, **Slovak Technical University, Trnava, Slovakia, *ruzena.kralikova@tuke.sk,**miroslav.rusko@stuba.sk

This Publication has to be referred as: Kralikova, R[uzena]; Rusko, M[iroslav]; Prochadzkova, D[ana] \& Emil, W[essely] (2015). Integrated Environmental Permitting Process in Slovakia, Chapter 31 in DAAAM International Scientific Book 2015, pp.359-368, B. Katalinic (Ed.), Published by DAAAM International, ISBN 978-3902734-05-1, ISSN 1726-9687, Vienna, Austria

DOI: $10.2507 /$ daaam.scibook.2015.31 
Kralikova, R.; Rusko, M.; Prochadzkova, D. \& Emil, W.: Integrated Environmental...

\section{Introduction}

The concept of ,integrated environmental protection" take into consideration all sectors of environment impacts like a complex instead of separated view on each sector particularly. The reason of this concept is that substances and emissions outflow from one environmental sector can cause transport to another environmental sector.

New attitude in integrated process represents change until now applied segment system of assessment and permitting installations to the integrated permitting. Integrated permit doesn't mean increased responsibilities contrariwise allow operators be actively connected to the permitting, transpose their own ideas in communication between competent authority and operator.

\section{Historical development of integrated prevention process}

Integrated permitting was introduced in Sweden in 1969, in Denmark in 1972, and in the United Kingdom in 1990 before being mandated across the European Union in 1996 by Directive 96/61/EC on Integrated Pollution Prevention and Control (IPPC). The basic principles of IPPC were laid out in the OECD Council Recommendation on Integrated Pollution Prevention and Control C(90)164 of 1991.

Directive 2008/1/EC of the European Parliament and of the Council of 15 January 2008 concerning integrated pollution prevention and control - the purpose of this Directive is to achieve integrated prevention and control of pollution arising from the activities listed in Annex I. It lays down measures designed to prevent or, where that is not practicable, to reduce emissions in the air, water and land from the abovementioned activities, including measures concerning waste, in order to achieve a high level of protection of the environment taken as a whole, without prejudice to Directive 85/337/EEC and other relevant Community provisions.

Environment is necessary condition of our existence and life. It is the only environment for life which we have. It is logical necessary to protect and develop this environment. The real guarantee like to preserve and improve present situation of environment are laws and their efficient enforcement.

\subsection{State in Slovakia}

Very important tool for upholding environmental laws to the practice are competent authorities which may give sanctions. The main execution of this tool in Slovakia is Slovak Inspectorate of Environment, which has been established by Slovak Ministry of Environment. Slovak Inspectorate of Environment (SIE) is skilled controlling authority, which makes state supervision and give sanctions to keep environment in good conditions and make state control in integrated prevention and pollution control section.

- For activities which SIE begin doing immediately after IPPC law comes into force, it was necessary to established new department and assign it personally, material and at the end also technically (Nitschneiderová, 2007). 
Headquarter coordinates the SIE work in national and international range. It works like a second degree - appeal authority to first degree decisions of local Inspectorates (SIE, 2015).

Under the terms of approximate process in conditions in Slovakia was set implementation of Council Directive 2010/75/EC from 24th November 2010 industrial emissions (integrated prevention and pollution control) and it was done by approving the Act 39/2013 - integrated prevention and pollution control (IPPC) and Regulation 183/2013, with which is fulfilled Act 39/2013 about IPPC.

Industrial emissions Directive has to easy competent authorities to specify integrated permission conditions.

Change from the Old Act of the IPPC is that the state supervisory authority during the process of updating permit conditions will require from operator to submit the baseline report and the first update after $15^{\text {th }}$ March 2013.

\section{Integrated permission}

Integrated permitting is process which is opened to general public. Except negotiate participants and competent authorities can also take part civil community of physical people, interest group of juridical people and people that can be connected with integrated permitting process.

Before publishing integrated permission preceded demanding and lengthy process which begins with sending operator a notification and continues with running negotiating application. Integrated process itself begins when operator submits an application and then ensue its processing and verifying information in installation. After oral hearing and each condition of permission is agreed with operator then is issued an integrated permission. To issue integrated permission lasts 60 days from oral hearing (it was 90 days in Old Act 245/2003 of IPPC) and maximum 5 months (it was 6 months in Old Act 245/2003 of IPPC) from the process beginning - from clear and right filled up application.

The system of integrated permitting brings different advantages in one hand for competent authorities on other hand for operators. System contribution can describe like:

- From the operator point of view: considerable simplifying of process because they need only one application for most decisions in environment protection sphere. The example of the application is compiled in way to be understandable and clear. In the case that the installation is new, integrated process is connected also with building permission. These aspects make process easier and speed it up.

- From the competent authorities point of view: advantage of this process is assessing the activities in permitting installation with one competent authority instead of existing permitting by different authorities with often complicated mutual interconnection. For this reason it's possible to set installation conditions with focus on all environmental impacts main in air protection, water protection and waste management area (Fig. 1). Because of this system the permits conditions inspections are simplifying because the inspections (out-side visits) made one competent authority. 


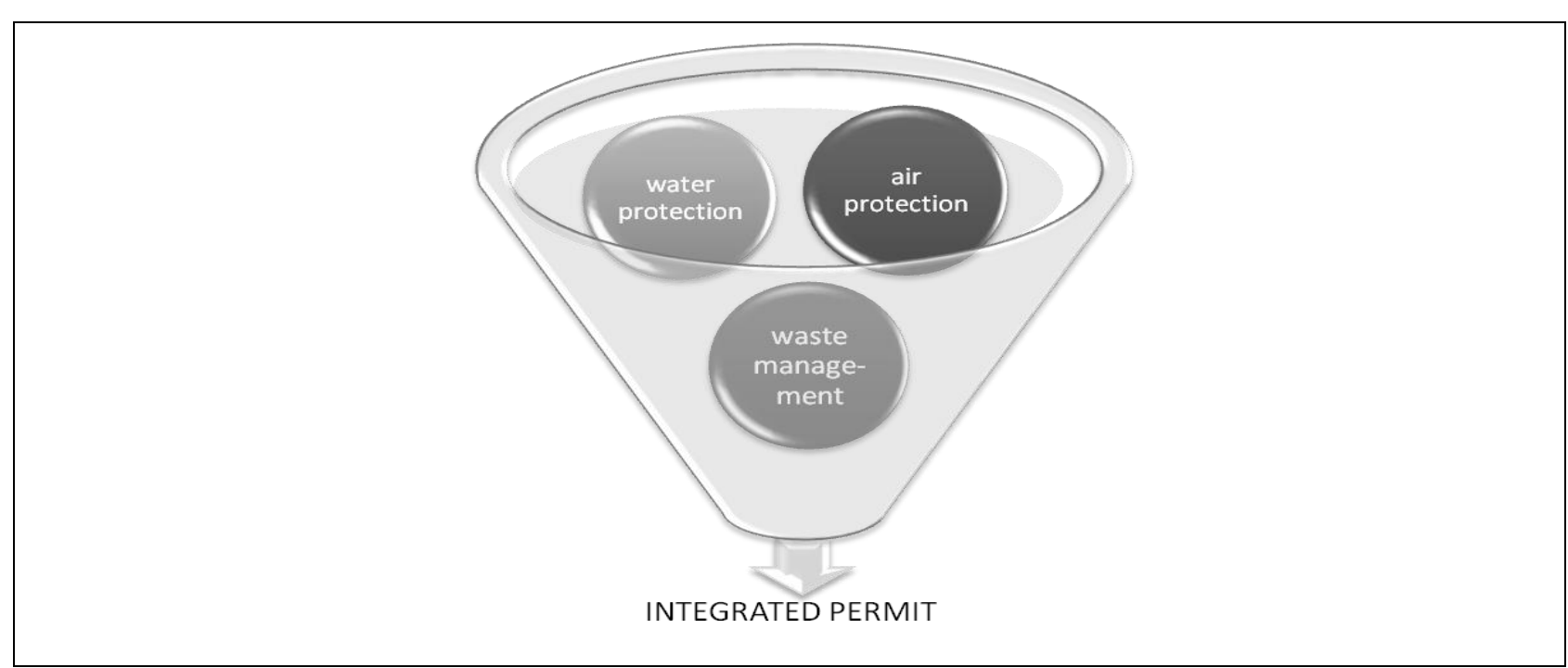

Fig. 1. Integrated process and its simplifying

For both sides is advantage that different approvals which up to the present are issued, are now concentrated in one well arranged document - integrated permit (Rusko, 2011).

\subsection{Permit conditions}

Integrated Pollution Prevention and Control - IPPC permit allows:

- whole control of the installation and confirms that if the conditions in the permit are following, the installation will not cause the environment pollution.

- With the IPPC permit the operator is obligated to use hierarchy of the waste management. The IPPC permit obligates the operator to use energy efficient.

- Obligates the operator to take measures for prevention of failures or reducing its consequences.

- After finishing the installation activities, IPPC permit obligated the operator to take some measures for location remediation and for bringing the environment in a satisfactory condition. With the IPPC permit the existence installations will be allowed to achieve the required condition in the specific time.

- IPPC permit obligates the operator to help during the inspection supervision.

- IPPC permit obligates the operator to supervise himself, to report for the regulations and to allow public access of the obtained data (Nitschneiderová, 2007).

Inspectors work not only like a permission competent authority but also like a state supervisory authority.

An IPPC permit is a living document - both reflecting the current performance at a facility and driving continual improvement on the part of the operator. Permit conditions that include implementation of an environmental management system and scrutiny of material inputs require operators on an ongoing basis to seek opportunities for performance improvement. Moreover, regulators and industry alike have an ongoing responsibility to keep abreast of the latest developments and improvements in BAT. On a real-time basis this knowledge may be directly applied to permit terms.

Long validity periods simplify the permitting system and reduce the administrative burden on both the government and industry. Environmental permits in 
most OECD countries are either valid for five to ten years or remain in force until other factors trigger a revision. A simplified procedure for amending a permit may be used in cases of administrative or small operational changes that do not affect permit conditions, or if there is a change of operator not entailing operational changes. Permits should be revised at the operator's initiative if changes are envisaged to the regulated process or if there are changes to the operator's ownership or contact information. A permit revision may be initiated by the competent authority if the applicable environmental quality objectives and/or standards have been modified (Kralikova, 2012).

\section{Overview of the regulatory process}

The entire regulatory process for IPPC consists of a number of elements. IPPC applies to specified 'installations', (both 'existing' and 'new'), requiring each 'operator' to obtain a permit from the enforcing authority - either the Chief Inspector (Tolsma, 2014).

\subsection{Permiting}

The procedure begins with the preparation of an application by the operator. The operator must cover various environmental issues. These include:

- Satisfactory environmental management of the installation;

- Adequate compliance monitoring;

- Assessment of polluting releases and the identification of BAT;

- Compliance with environmental quality standards (EQSS), other european directives and domestic regulations;

- Energy efficiency, waste minimisation and management; and

- The prevention of accidents.

\subsection{Operation}

Once the Chief Inspector has issued a permit, the operator of an IPPC installation will have to carry out monitoring to demonstrate compliance with the permit conditions. The Chief Inspector will also carry out his own monitoring and inspections, and have a range of enforcement powers.

\subsection{Closure}

When an installation closes, an operator should apply to surrender a permit, to end regulation under IPPC. The operator is required to identify any steps that have been taken to avoid any pollution risk resulting from the operation of the installation or return it to a satisfactory state. Chief Inspector shall accept the surrender and give the operator notice of its determination. The permit shall then cease to have effect on the date specified in the notice of determination. If the Chief Inspector is not satisfied, he shall give notice of his determination stating the application has been refused.

Table 1 shows overview of the legal binding permits based on 2014 year in Slovak republic (SIE, 2015). 
Kralikova, R.; Rusko, M.; Prochadzkova, D. \& Emil, W.: Integrated Environmental...

\begin{tabular}{|c|c|c|c|c|c|c|c|}
\hline \multicolumn{7}{|c|}{ Sector of Industry } & \multirow[b]{2}{*}{$\sum$} \\
\hline $\begin{array}{c}\text { PowerE } \\
\text { nergy }\end{array}$ & $\begin{array}{c}\text { Metal } \\
\text { Metalurgy }\end{array}$ & Mineral & Chemistry & $\begin{array}{c}\text { Waste } \\
\text { Treatment }\end{array}$ & Other & $\begin{array}{l}\text { Without } \\
\text { category }\end{array}$ & \\
\hline 80 & 73 & 65 & 62 & 102 & 99 & 1 & 100 \\
\hline
\end{tabular}

Tab. 1. The overview of the legal binding permits based on 2014 year

On the Figure 2 is possible to see trend in number of realised regulary cheks from 2004 to 2014 in Slovakia.

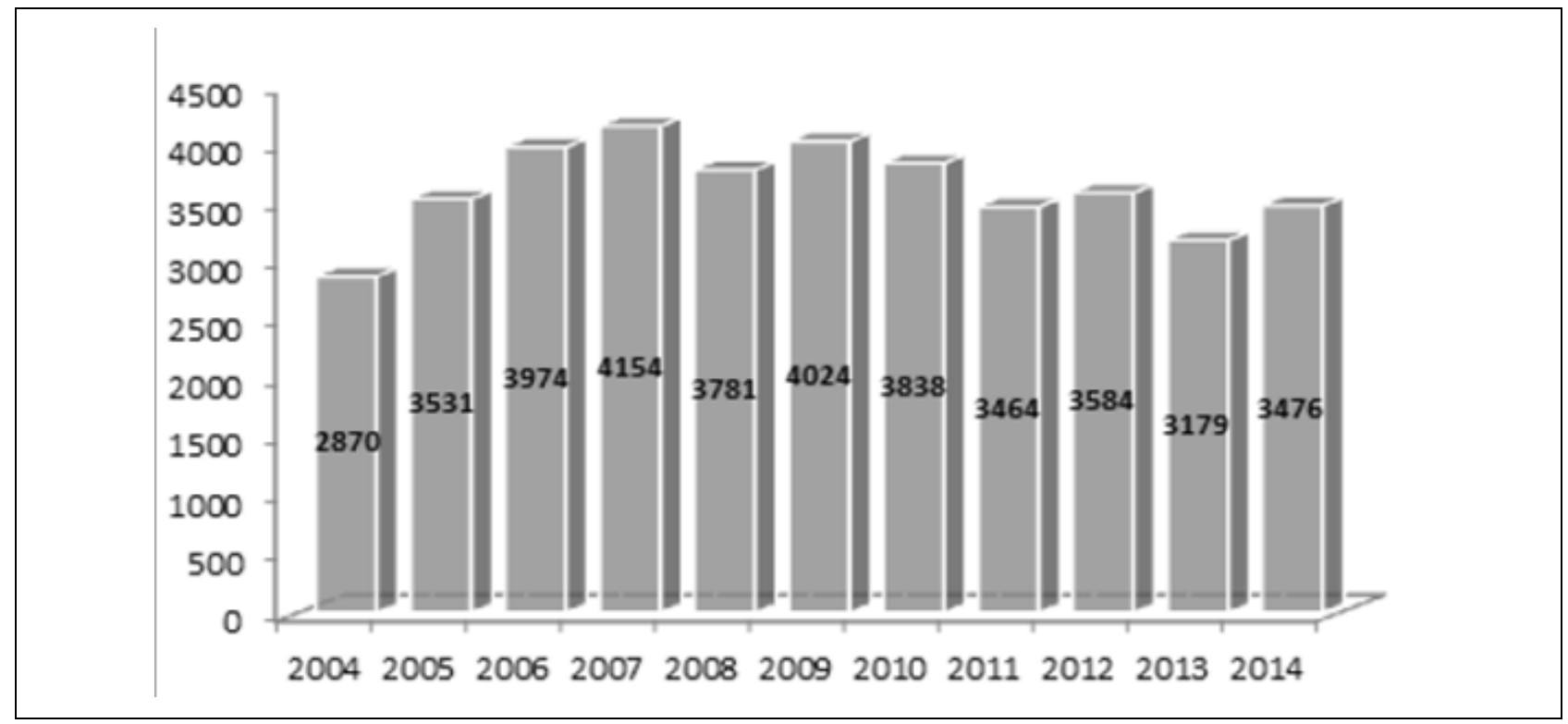

Fig. 2. Trend in number of realised regulary cheks (2004-2014)

\section{BAT and BREFs}

The main target of integrated prevention is to protect environment like a whole before industrial and agricultural pollution by regulating installations. It is possible to achieve higher degree of environmental protection by using BAT (Suchanek, 2004).

IPPC Directive for this purpose introduces new conception known as BAT - Best Available Technique. BATs are defined as most effective and developed degree of development using technologies and the way of their operation. They are made to be enabling set up in applicable economic branch. Conditions must be economic and technical acceptable with respect to expenses and contributions. Installation operator can accept conditions only when they are reasonable and at the same time must be most effective in protection environment as a whole.

Articles 13 to 16 of the Industrial Emissions Directive require that BAT reference documents are the reference for setting permit conditions and that emission limit values do not exceed the emission levels associated with the best available techniques as described in those BAT reference documents. Article 13 states that the exchange of information in best available techniques shall take place between the member states, industries concerned and environmental NGOs. This is the so called Sevilla Process, which helps to determine best available techniques Figure 3. 


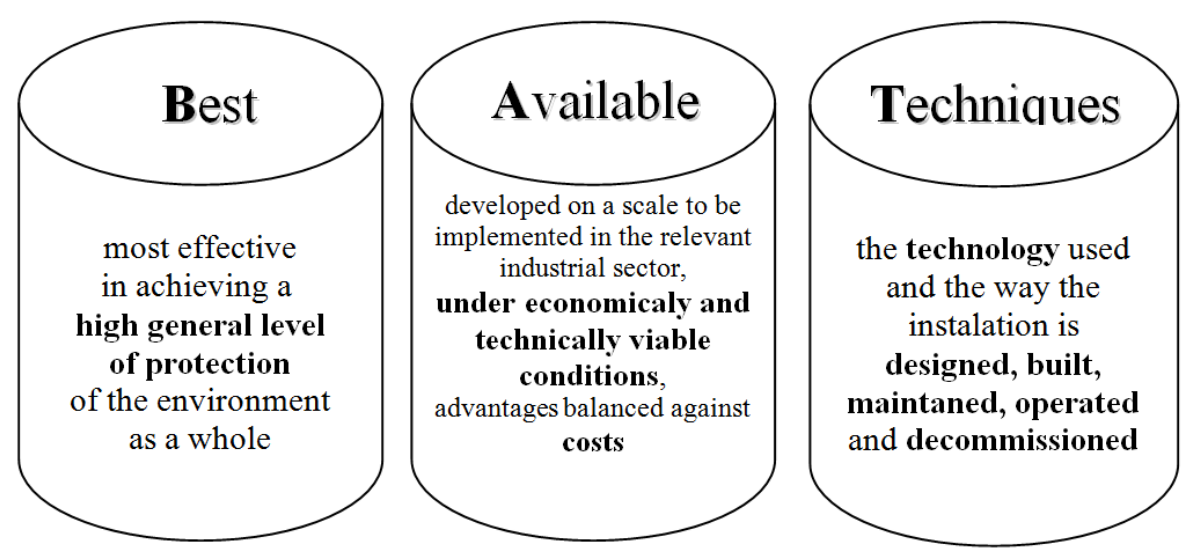

Fig. 3. Best available techniques (Eracomm, 2014)

\subsection{Using of BREF in the Permit}

The result of formal change of information has form of BAT Reference Documents - BREFs. They are gradually published for all activities which are under IPPC. BREF is the tool through which BAT and emerging techniques are determined in a transparent manner, based on sound techno-economic information. Therefore, BAT conclusions are their key elements.

BREFs summarized and recommended (but not obligatory) Best Available Technique in given industrial branch. BREFs are prepared by TWGs (Technical working groups) and are used as a background papers for integrated permit applications. TWGs consist of experts from EU countries, EFTA countries (European Free Trade Association) and associated states which represent industrial and nongovernmental environmental organizations. These technical working groups prepare BREFs on the base of obtained information. On exchange these information oversee IEF (Information Exchange Forum) which is meets twice or thee time in year and give official comments to BREFs proposals, Figure 3.

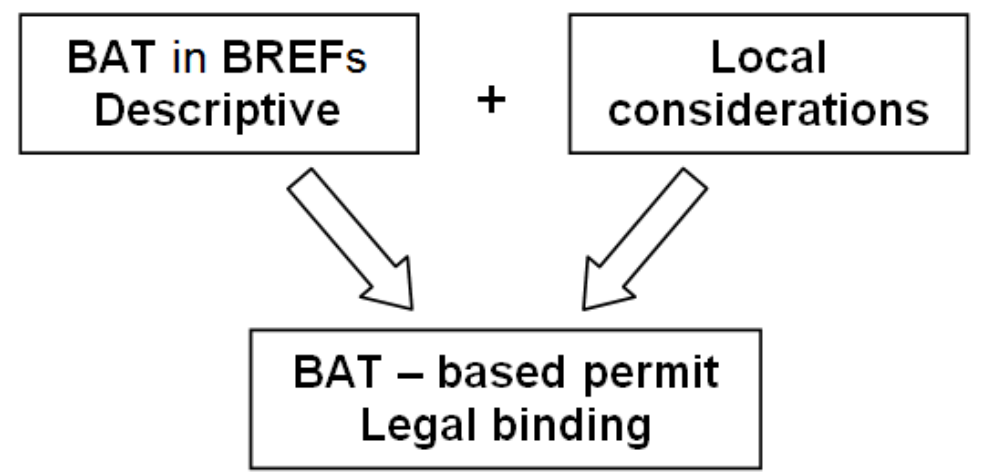

Fig. 4. From BREF to Permit Condition

The BREFs target is to provide information about:

- given industrial branch,

- used technologies and processes, 
Kralikova, R.; Rusko, M.; Prochadzkova, D. \& Emil, W.: Integrated Environmental...

- materials flows,

- emissions limits in EU member states,

- emissions monitoring by relevant authorities of EU member states, by installation operator, by European Commission and finally by general public.

If in integrated permit will be allowed higher value, as indicated in the BREF (higher than specified in the European Commission decision on BAT conclusions), these emission limit value will have to be permitted by Paragraph 15 of IED as an exception. If the exemption reasoning will not the Commission considered relevant, will followed an official announcement that Slovakia does not fulfil the IED requirements and the European Commission shall set a deadline for the investigation and remediation (e.g. one year). If there will be no correction, the European Commission shall give notice to the European Court for sanctions against Slovakia.

Existing industrial installations will need management strategies for compliance with integrated permitting requirements and time to make the necessary investment. Even for new installations, integrated permitting cannot be made operational immediately because of the need to create appropriate legal and institutional arrangements and prepare technical guidance. Therefore, it is important to phase the introduction of integrated permitting by setting priorities among industrial sectors. The criteria for such prioritisation include the environmental impact, anticipated compliance costs, economic and financial conditions of the industrial sectors concerned, as well as administrative capacity constraints of the permitting authorities. Different compliance deadlines for new and existing installations should also be established (Kralikova, R. et al. 2012).

It must be noted that many operators still consider that in compliance with BAT mean the compliance with emission limits to air. They do not realize that BAT by means of BREF also defines limit values for emissions to water, soil and threshold parameters for example - for organic substances content in the starting materials or materials which are take into account energy efficiency across production, follows the material and energy flows, production and waste management etc. In fact, there can be situation when the installation that complies with the emission limits for pollutants into the air, will not be in accordance with BAT in other parameters, for example: energy efficiency of production or the contents of organic substances in the input material. Replacement with new material may be economically difficult for installation, sometimes liquidating. Actual costs to comply with BAT are expected very high.

\section{Discussion}

When we are talking about IPPC installations, the main principle of integrated permitting is the compliance of the installation with emission values in best available techniques. In Slovakia especially in industry, with several operating devices are at the border, respectively after the border of his life, is entitled to a presumption of high economic performance into line with BAT. Issued integrated permits indicate that in 
many cases emission limits were set up for existing installations in accordance with the emission limits which are in component implementing Acts and Regulations and not from BAT. As already stated, the emission limit values set out in the annexes to the IED are only minimum requirements for exemption which may be granted only in justified exceptional cases and right in the IPPC permit. Each case will have to be reported to the European Commission.

Changes to IPPC permits may be initiated by the facility or permitting authority to reflect operational or process changes at the facility, changes in BAT, or changes in facility performance. Permit revisions can tighten or loosen permit obligations, but must continue to reflect BAT for the facility. Prior to making an operational or process change, an operator must notify permitting authority and assess the environmental effect of the proposed change before it is actualized. The permitting authority (usually the area inspector) then determines whether a change requires a permit variation (EPA, 2008).

The core of each BREF is row of elements which lead to identification what can be consider as a BAT. It is done on previous information and specific emissions limits set for industrial branch. At the end of each BREF is information about developing techniques in given industrial branch. In any case BREF documents should not contain political views and attitudes.

Information ensure - especially for new activities and installation which are concerned in the Industrial Emission Directive (IED) and increase the emphasis on BAT from previously collected knowledge of the period of preparing the IED is evident that a major barrier especially for new or smaller installations. There is the lack of information, especially on a major role in the clearance of BAT, respectively the BREF. BAT requirements, which become binding cover the entire production process material and energy flows, including efficiency in the use of raw materials, fuel and energy, generation and management of waste, as well as other emissions area - release of substances, vibrations, heat or noise not only into the air but also to water or soil. For effective implementation and enforcement of IED should the authorizing authority of Slovak Environmental Inspectorate (SEI) - regularly report on compliance. It is required to ensure that the operator and the SEI to take the necessary arrangements in case of non-compliance with IED. Therefore, in SEI should be an adequate number of inspectors with the necessary skills and qualifications to carry out inspections effectively. IED requires setting permit conditions based on BAT, which result reference documents BREF.

Therefore, is necessary to ensure the participation of Slovak experts - experts in manufacturing, research and academia in the process of BREF. In Slovakia is necessary their mutual communication, cooperation and assistance for SEI in applying requirements of BREF in the authorization process. It is therefore necessary to have reference document translations in Slovak language. To support these requirements, it is necessary to establish a forum - center with the required personnel and financial resources to ensure these activities in Slovakia. 
Kralikova, R.; Rusko, M.; Prochadzkova, D. \& Emil, W.: Integrated Environmental...

\section{Conclusion}

Integrated permitting is process in which are set conditions for defined industrial activities in installations. New installations are permitted to meet the target - integrated environmental protection and protection of all environmental sectors, to keep the pollution degree in environmental quality standards. The main target of integrated prevention is to protect environment like a whole before industrial and agricultural pollution by regulating installations. In spite of integrated permitting is still relatively new problematic in markedly lesser extend come to breaking of duties which followed from integrated permits. The operators, which are under the IED Directive, are satisfied, that they don't need to ensure so many permits from different competent authorities as in the past. All conditions of installation operation are contained in one integrated permit. Integrated permit doesn't mean increased responsibilities contrariwise allow operators be actively connected to the permitting, transpose their own ideas in communication between competent authority and operator what existing practice doesn't allowed.

\section{Acknowledgment}

This contribution was worked - out frame within the frame project VEGA 1/0990/15 (33\%), APVV (34\%) and (33\%).

\section{References}

Nitschneiderová, H. (2007). SIE successfully deals with European Union tasks in integrated permitting. Enviromagazín, Slovakia, Ministry of Environment, Vol. XII, No. 6, pp. 4-5

ASPEK (2010). A study of the impact of industrial emissions on Industry and Energy Slovak Republic, Association of Industrial Ecology in Slovakia, September 2010 Rusko, M. ; Tureková, I. \& Očenášová, I. (2011). Integrated Prevention and Pollution Control as an Important Tool of Environmental Policy in Slovak Republic, Research Papers. Vol.18, Issue 28, March 2011, pp 141-148, ISSN 1336-1589.

Slovak Inspectorate of Environment (2015). Annual report 2014, ASPEK, March $2015,120 \mathrm{p}$

Tolsma, D., H. (2014). Improving environmental Permitting Systems: Integrated Permits in the Netherlands, International Public Administration Review, Vol. XII, No. 2-3/2014, pp .81-98

EPA(2008). An In-depth Look at the United Kingdom Integrated Permitting System, Exploring Global Environmental Protection Perspectives, Executive Summary, July 2008, EPA-100-S-08-001

Kralikova, R. ; Prochadzkova, D. ; Rusko, M. \& Wessely, E (2012). Proposal of character of future Europe union security research, $23^{\text {rd }}$ DAAAM . 2012, 1, pp. 19-24 ***https://www.eracomm.eu/EU_Law_on_Industrial_Emissions/module_2/bat.html, Modul 2 - BAT -BREFs. Accesed on: 2015-01-11

$* * *$ Slovak Act No 39/2013. Integrated prevention and pollution control (IPPC). ***The IPPC Directive No 2008/1/EC 